Performance of a $512 \times 512$ Gated CMOS Imager with a 250 ps Exposure Time

A. T. Teruya, S. P. Vernon, J. D. Moody, W. W. Hsing, C. G. Brown, M. C. Griffin, A. S. Mead, V. Tran

August 8, 2012

SPIE Conference

San Diego, CA, United States

August 12, 2012 through August 15, 2012 
This document was prepared as an account of work sponsored by an agency of the United States government. Neither the United States government nor Lawrence Livermore National Security, LLC, nor any of their employees makes any warranty, expressed or implied, or assumes any legal liability or responsibility for the accuracy, completeness, or usefulness of any information, apparatus, product, or process disclosed, or represents that its use would not infringe privately owned rights. Reference herein to any specific commercial product, process, or service by trade name, trademark, manufacturer, or otherwise does not necessarily constitute or imply its endorsement, recommendation, or favoring by the United States government or Lawrence Livermore National Security, LLC. The views and opinions of authors expressed herein do not necessarily state or reflect those of the United States government or Lawrence Livermore National Security, LLC, and shall not be used for advertising or product endorsement purposes. 


\section{Performance of a 512 x 512 Gated CMOS Imager with a 250 ps Exposure Time}

SPIE Optics+Photonics 2012

August 14, 2012

A. T. Teruya, S. P. Vernon, J. D. Moody, W. W. Hsing,

C. G. Brown, M. C. Griffin, A. S. Mead, V. Tran

\section{LLawrence Livermore National Laboratory}

This work was performed under the auspices of the U.S. Department of Energy by Lawrence Livermore National Laboratory under Contract

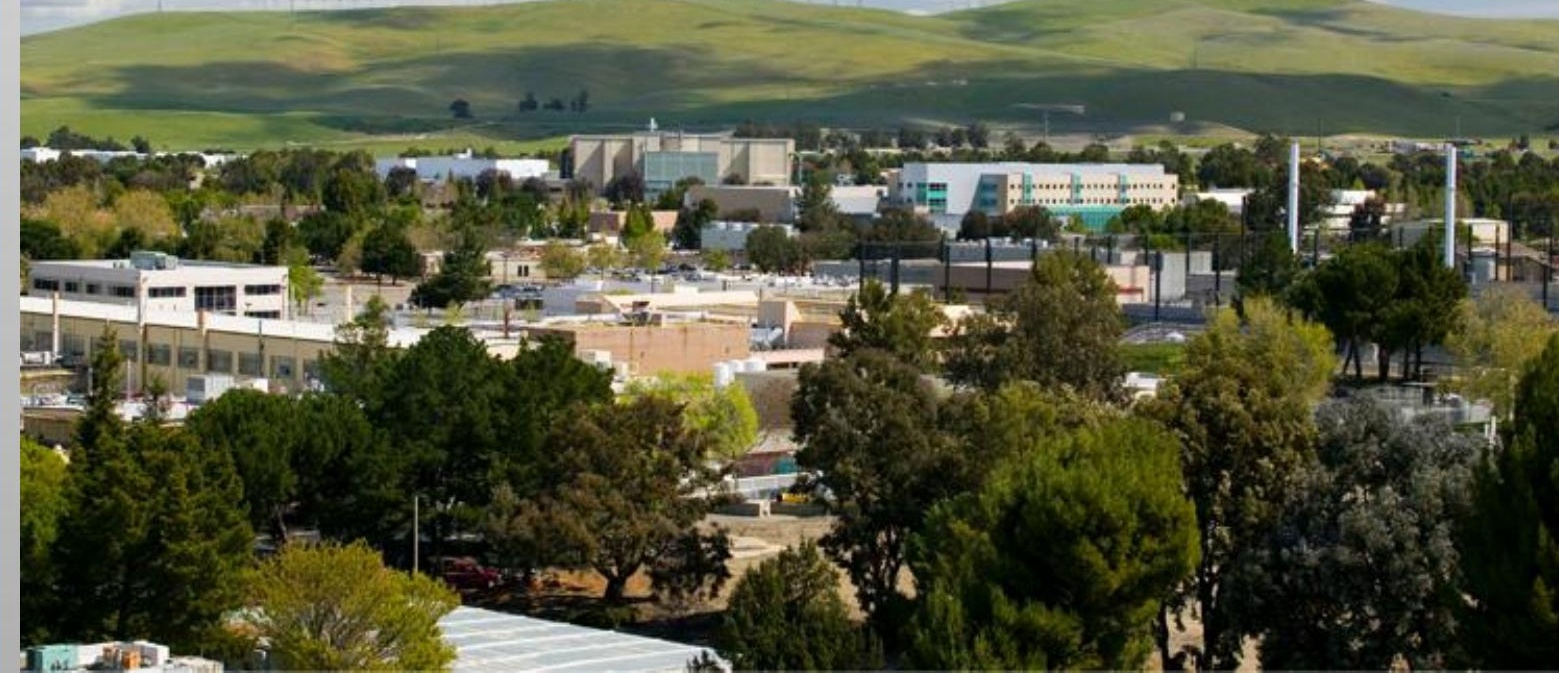




\section{Collaborators}

- LLNL

- Elden Abels, Rich Bionta, Warren Hsing, Jim Moody, Ted Perry, Harry Robey, Vern Rekow, Alan Teruya, Steve Vernon, Franz Weber

- Massachusetts Institute of Technology - Lincoln Laboratory (MIT-LL)

- Bob Berger, David Craig, Dennis Rathman, Bob Reich, Antonio Soares

- National Security Technologies, Inc. (NSTec)

- Chris Brown, Matt Griffin, Kris Larsen, Andy Meade, Vu Tran, Pete Torres 


\section{Outline}

- NIF applications for gated x-ray imaging

- Requirements for a solid state sensor

- Multi-frame, solid-state gated imager conceptual design

- 64x64 pixel prototype characterization

- 512x512 imager concept

- ROIC characterization

- X-ray sensor design and fabrication concepts

- Future work 


\section{NIF has a need for gated imaging}

- Current imaging technologies used by LLNL

- Time integrated - No temporal information

- Gated - Complicated and difficult to calibrate and maintain

- MIT-LL has developed CMOS technology that can trigger an imaging sensor with sub-ns gates

- Testing is done at the $<100$ ps Short Pulse Laser (SPL) and 100 ns Long Pulse Laser (LPL) laboratories, at NSTec - Livermore Operations 


\section{The Static X-Ray Imager takes X-ray pinhole images}
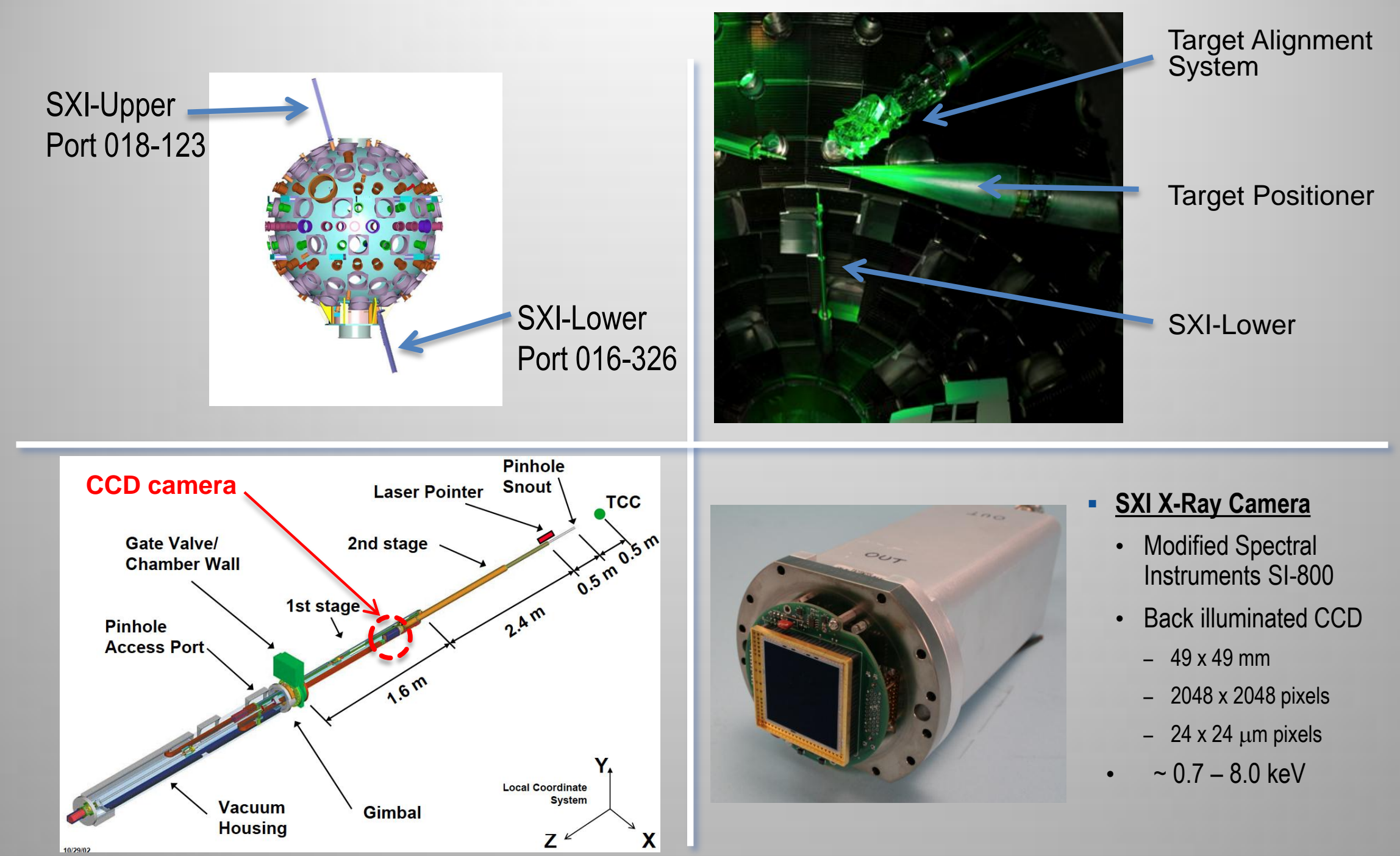

\section{- SXI X-Ray Camera}

- Modified Spectral Instruments SI-800

- Back illuminated CCD

- $49 \times 49 \mathrm{~mm}$

- $2048 \times 2048$ pixels

- $24 \times 24 \mu \mathrm{m}$ pixels

- $\quad \sim 0.7-8.0 \mathrm{keV}$ 


\section{SXI measures the laser entrance hole (LEH) size to correct $\mathrm{X}$-Ray emission measurements by other diagnostics}

Experimental SXI image $1 \mathrm{MJ}$ shot, 3-5 keV channel

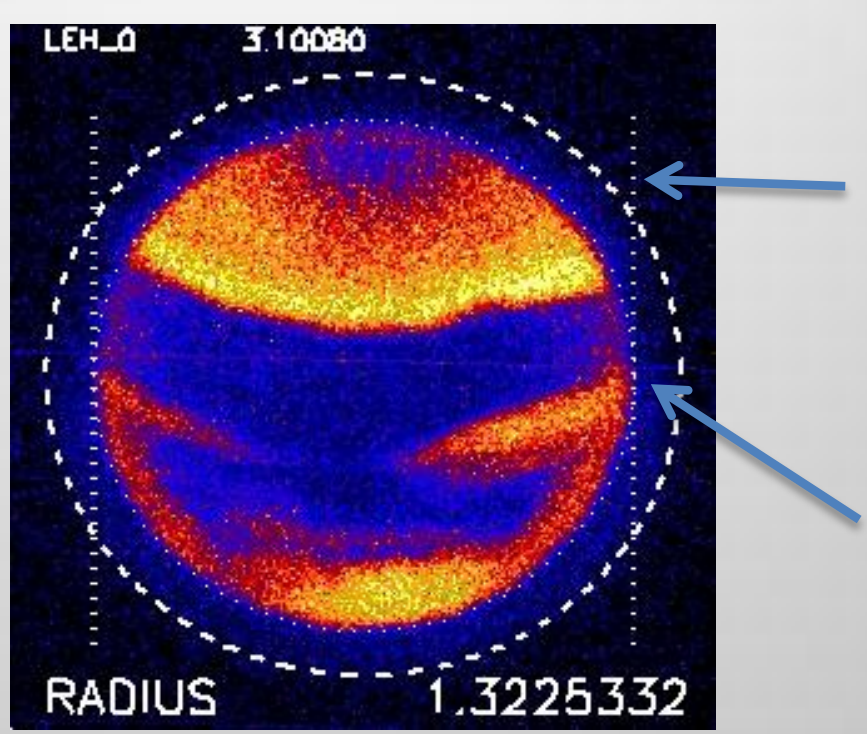

Original LEH (dotted circle)

Measured LEH

- SXI provides a time integrated image of the LEH aperture

- Gated images would provide a better measurement of the clear aperture as it varies in time 


\section{A gated imager provides time resolved $X$-ray pinhole imaging of imploding cores}

- Gated X-ray Detector (GXD)

- Spectral sensitivity from 200 $\mathrm{nm}$ to $17.5 \mathrm{keV}$

- Four $7.5 \mathrm{~mm}$ strip lines

- Temporal window adjustable $200-1500$ ps

- Independent gain, gating for each strip

- Spatial resolution $\leq 60 \mu \mathrm{m}$ at image plane
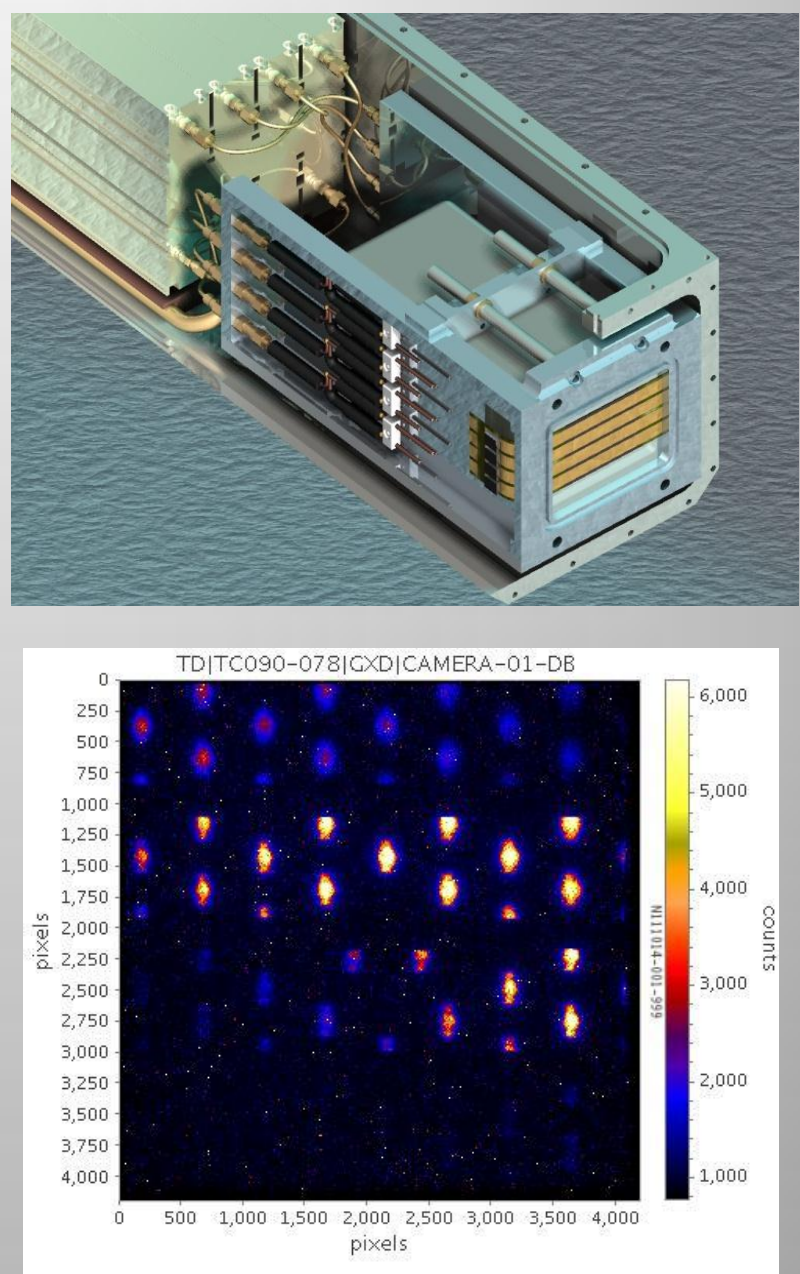

Image courtesy of Steve Glenn, LLNL 


\section{Requirements for a solid state sensor}

- Need a user selectable gate duration varying between 10 ps and $1 \mathrm{~ns}$

- Applications require spatial resolution of $20 \mu \mathrm{m}(10$ $\mu \mathrm{m}$ is better) at the target (typical magnification is $2 x$ for SXI, $4 x$ to $15 x$ for other diagnostics)

- All applications require multiple frames, preferably taken along a single line of sight

- Experiments require imaging at $\mathrm{X}$-ray energies from $1 \mathrm{keV}$ to $50 \mathrm{keV}$ 


\section{Technology development plan}

- Development of a CMOS readout integrated circuits (ROIC)

- Selectable gate lengths

- Multiple frames

- Two stages

$-64 \times 64$ prototype to test gate distribution

$-512 \times 512$ ROIC

- Development of application specific sensors

- Bump bond sensor arrays to ROIC 


\section{$64 \times 64$ pixel prototype demonstrated trigger distribution and gate generation}

- $\mathrm{H}$-Tree structure distributes gate trigger to 8x8 pixel neighborhoods with low skew

- Pulse delay and NAND gate circuitry in each $8 \times 8$ neighborhood locally generates a gate pulse of desired length
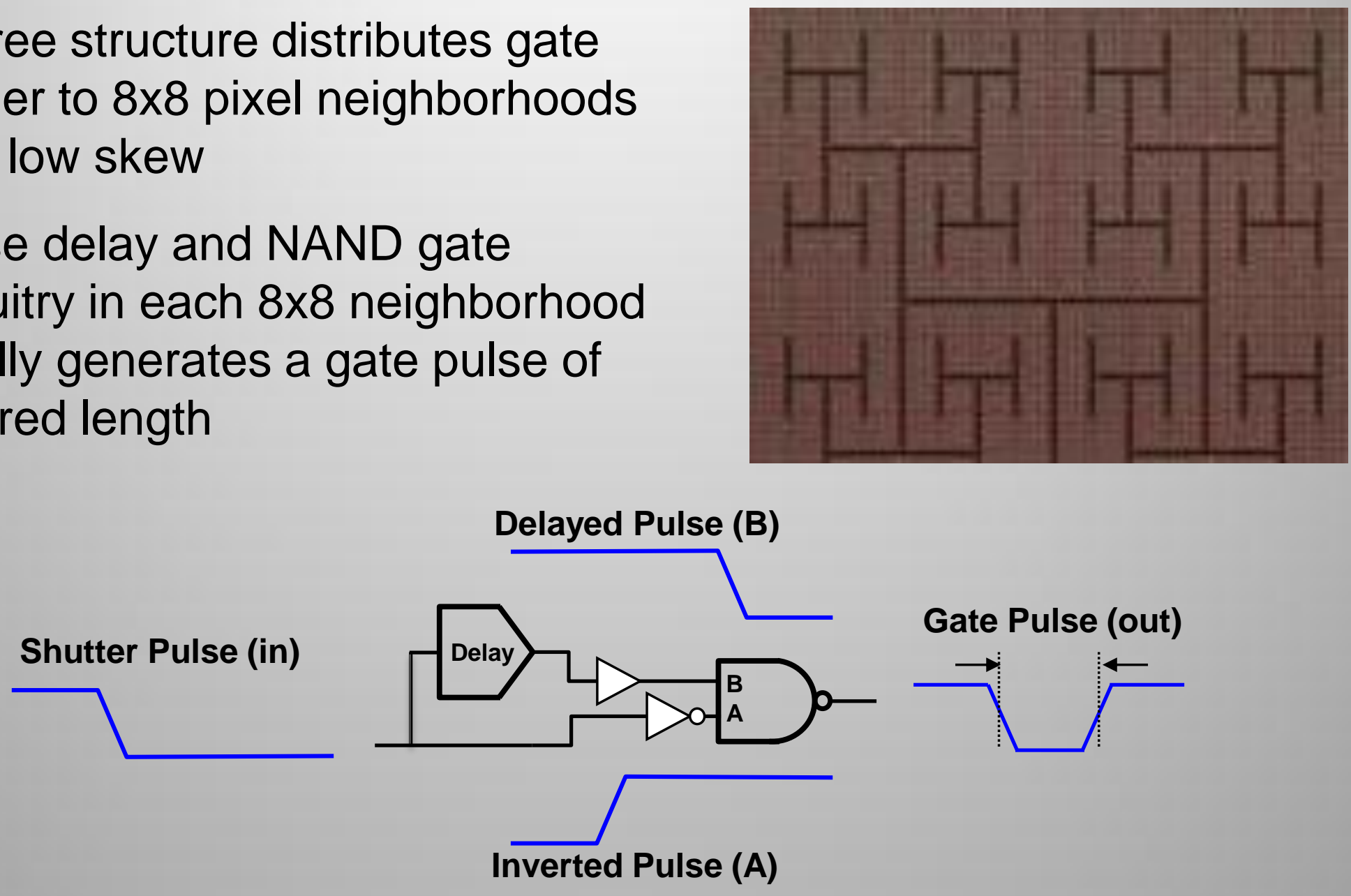


\section{Architecture of the $64 \times 64$ prototype}

Test Chip Layout (Background image)

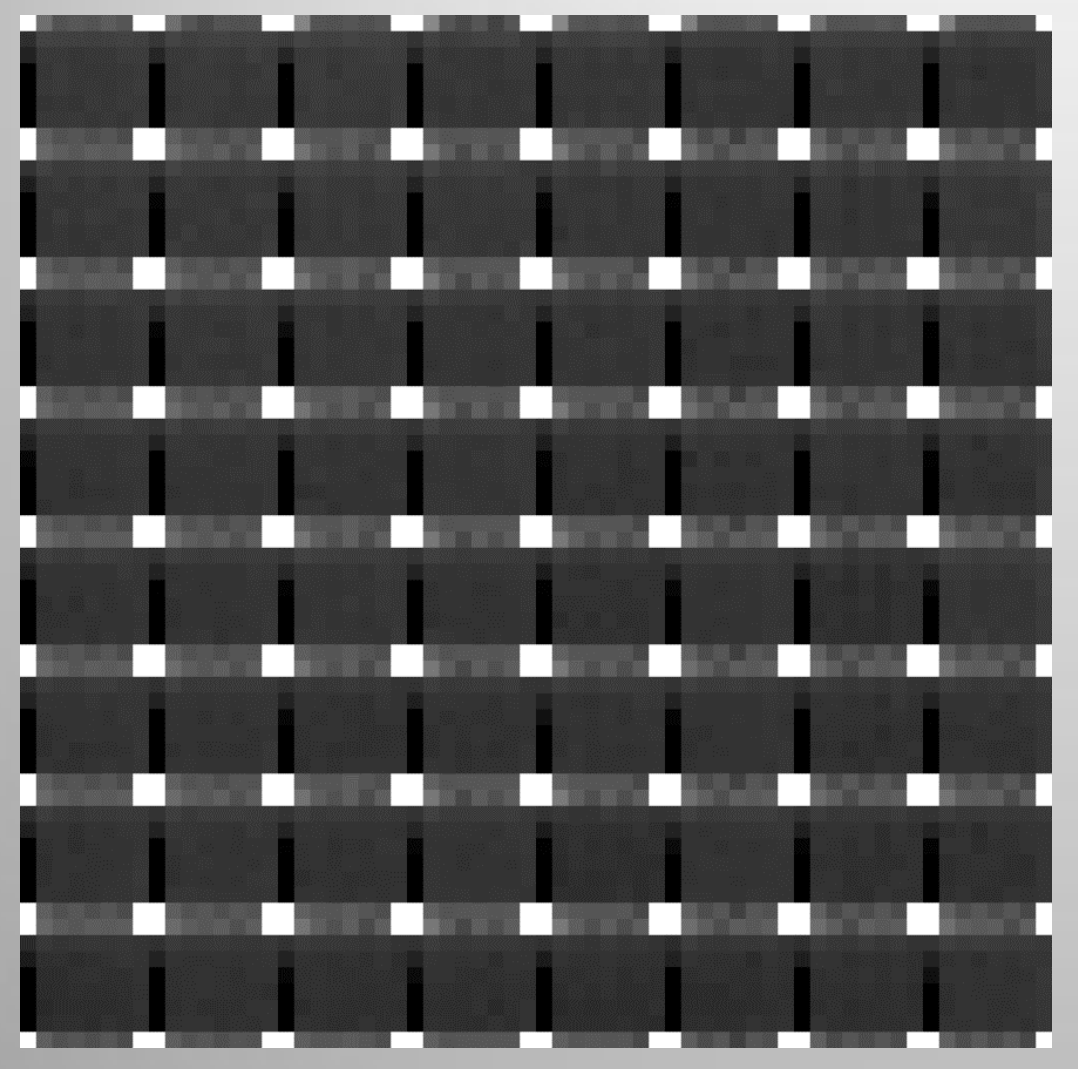

- 8x8 pixel neighborhoods contain $6 \times 7$ sensor pixels surrounded by test structure pixels

- Test structure pixels are set to known voltages or currents 


\section{Optical tests of the $64 \times 64$ pixel prototype with a 200 fs laser validated low skew}

Illumination with a $400 \mathrm{~nm} \sim$ Gaussian beam ( $\left.t_{\text {pulse }} \sim 200 \mathrm{fs}\right)$

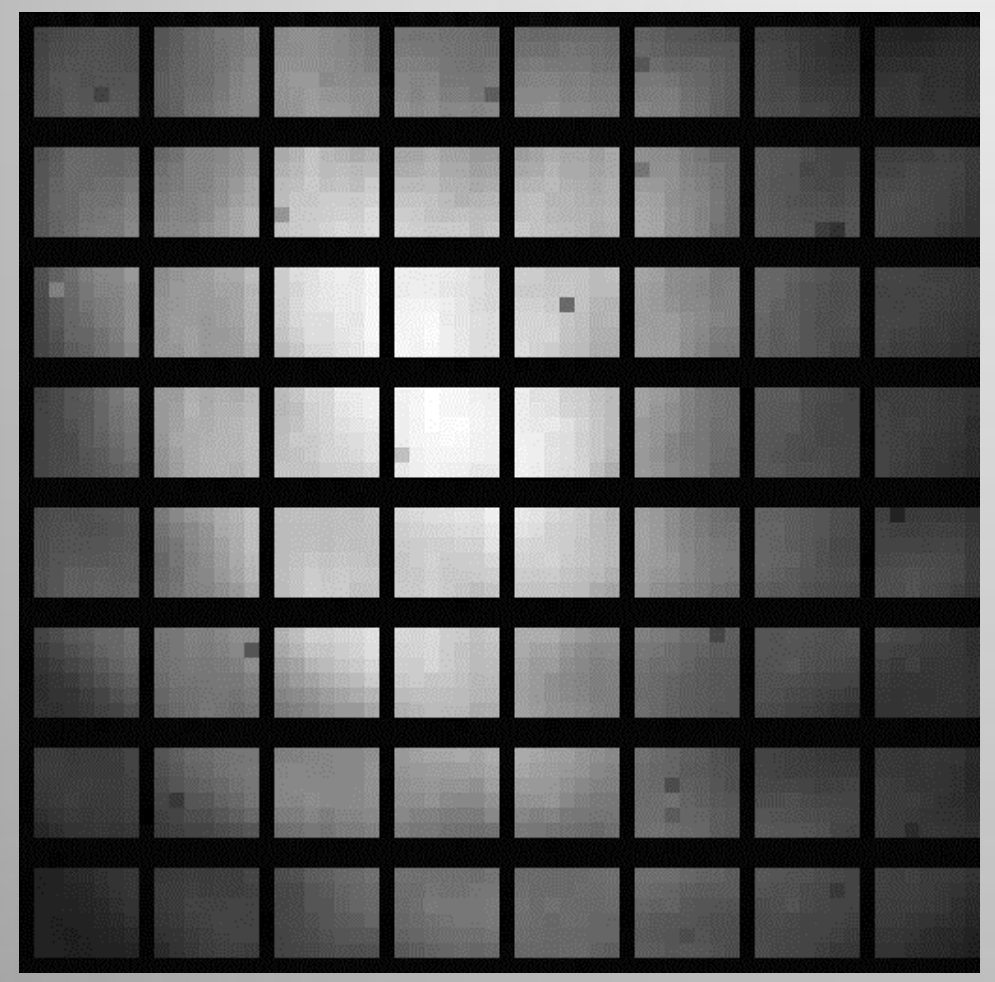

Image Taken During Peak of Gate

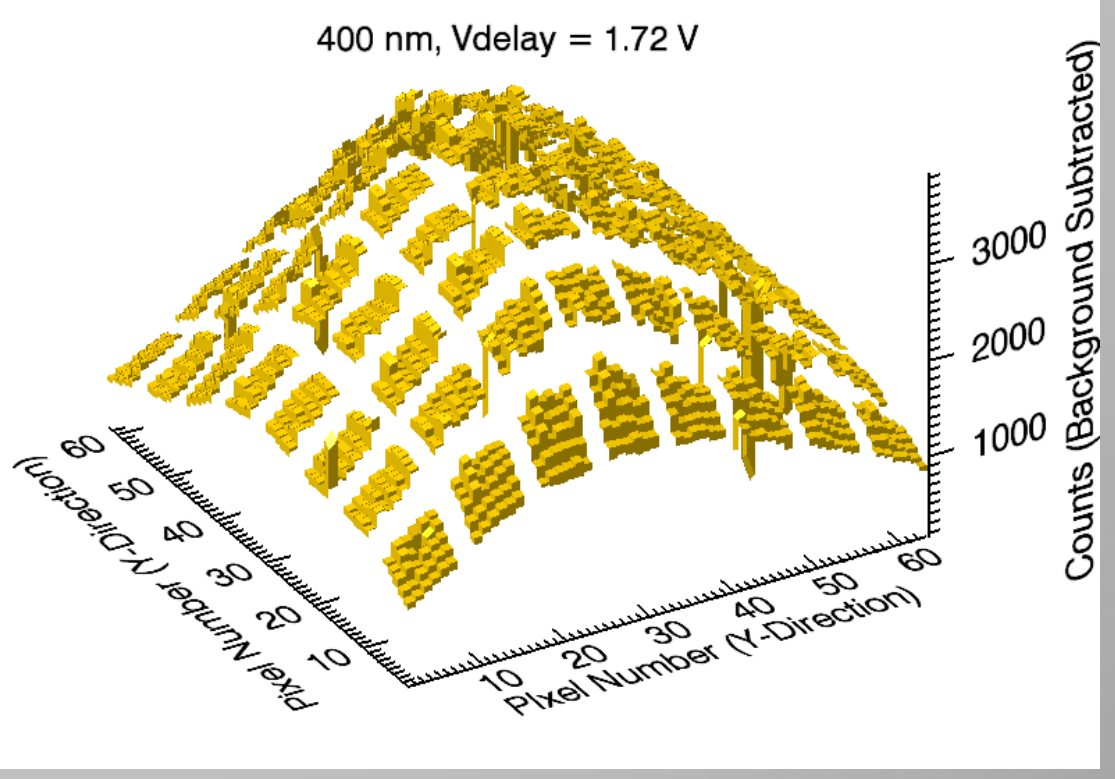




\section{Optical tests with a 200 fs laser validated local gate generation}

- Illumination with a $400 \mathrm{~nm} \sim$ Gaussian beam ( $\left.t_{\text {pulse }} \sim 200 \mathrm{fs}\right)$

- Gate length set by analog voltage $V_{\text {delay }}$
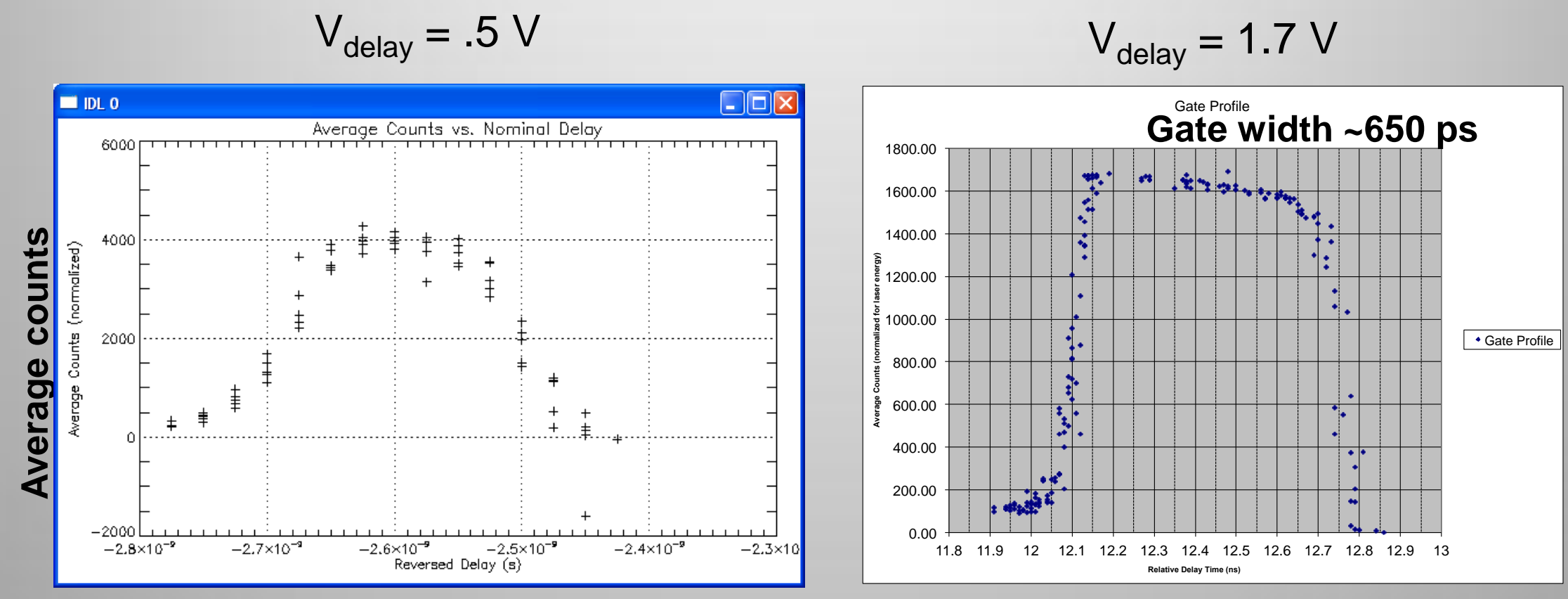

100 ps/ major division

Demonstration of local generation of $\sim 200$ ps to $\sim 650$ ps gates 


\section{Success of the prototype led to development of a $\mathbf{5 1 2} \times \mathbf{5 1 2}$ ROIC}

- 8x expansion of $\mathrm{H}$-tree structure

- 4 quadrants may be triggered independently or in common

- Pads for bump bonding photodiode array

- Photosites for optical testing

- Design Specifications

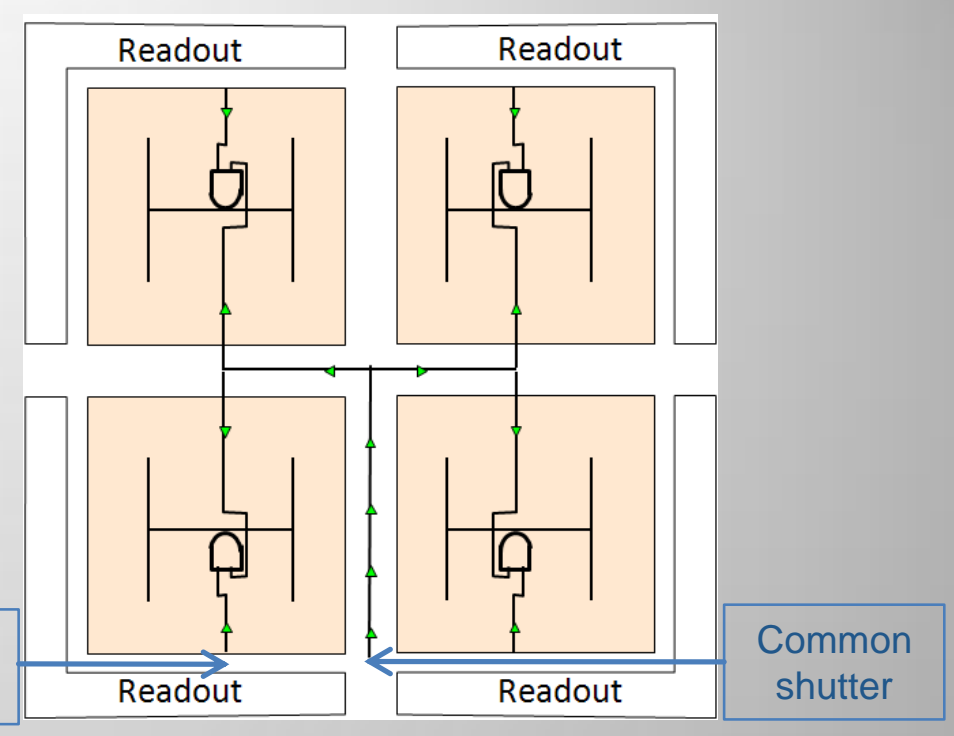

- $30 \mu \mathrm{m}$ pixel

- Fill-factor

- $<10 \%$ on-chip

- $>90 \%$ bump bonded

- Timing

- Jitter <50 ps

- Skew <100 ps

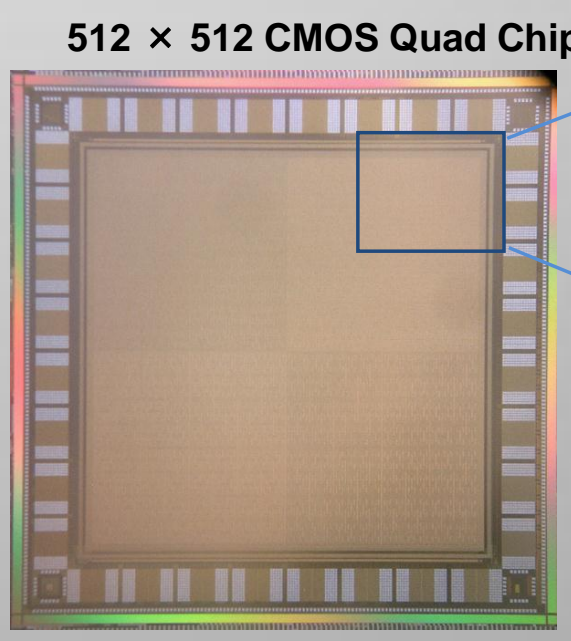

H-tree Network

Pixels

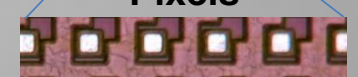

달ㄷㄹㄷㅏ 


\section{The ROIC was integrated into a custom}

\section{camera}

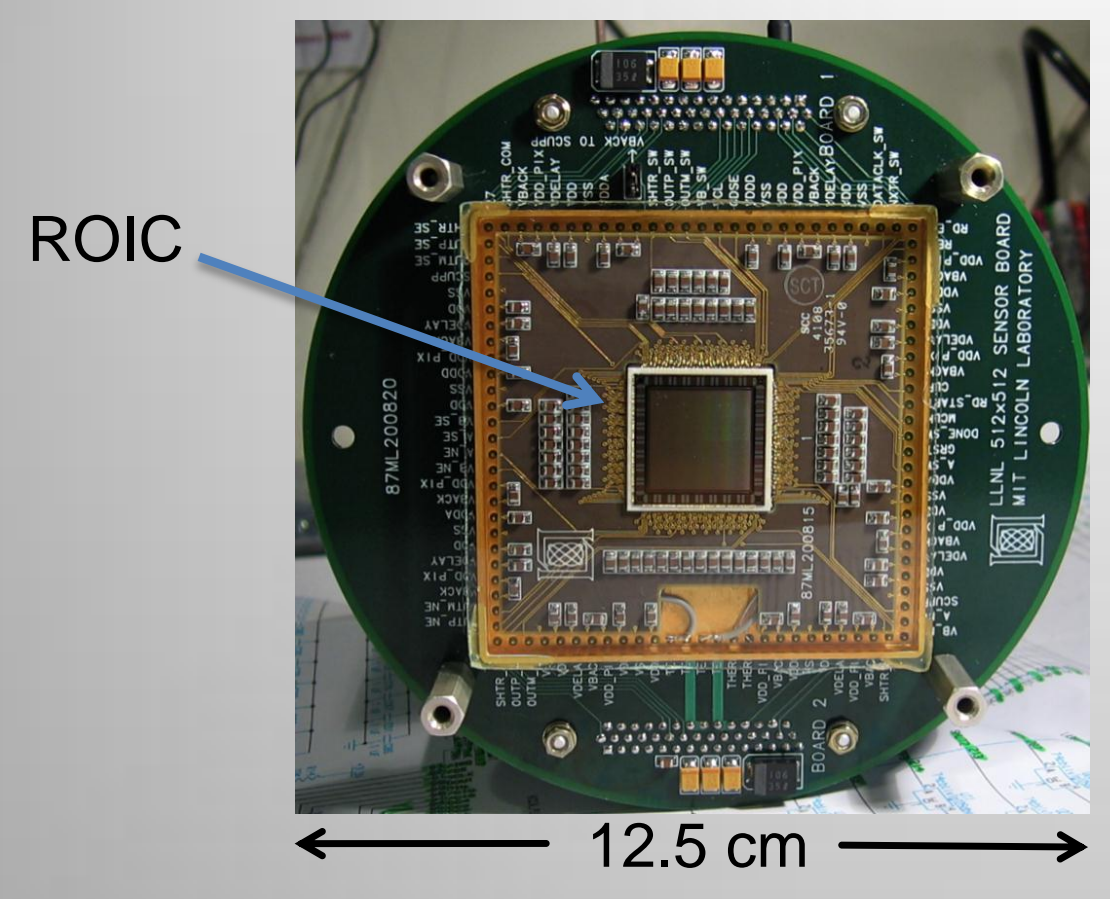

- Each quadrant has is read out by an ADC

- A housing allows thermoelectric cooling in a dry nitrogen atmosphere

- A photosite built into each pixel allows testing with UV or X-ray illumination

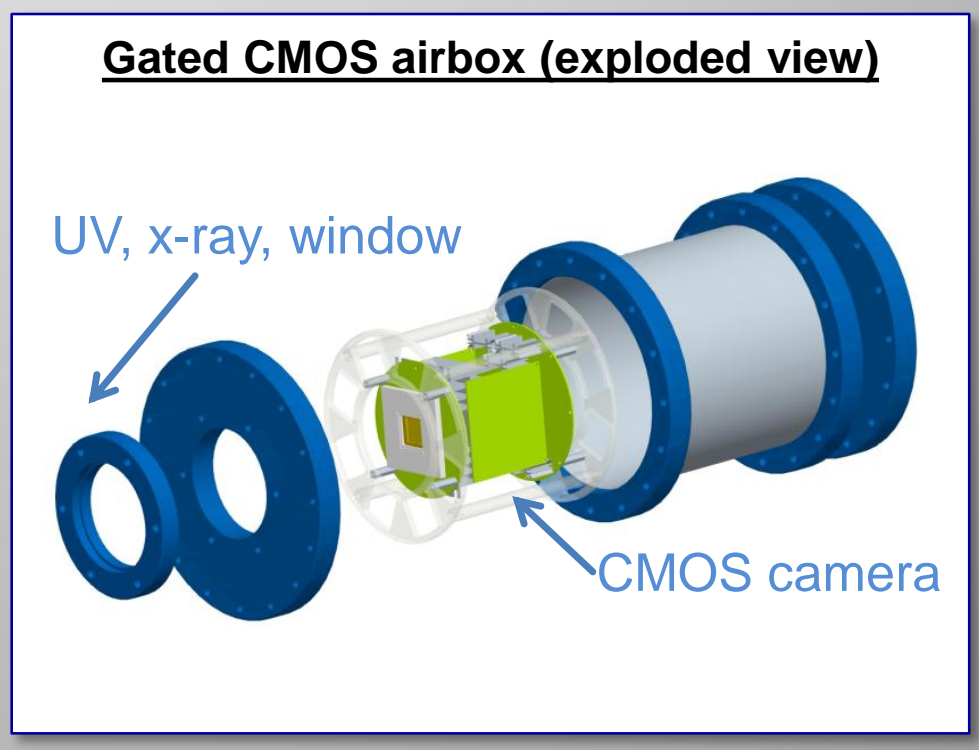




\section{Gate profile measurements}

- A frequency-doubled (400 nm) 50 fs Ti:sapphire laser system was used to measure the gate profile

- The measurement was made by varying the delay time between the shutter trigger pulse and the arrival of the laser pulse at the sensor
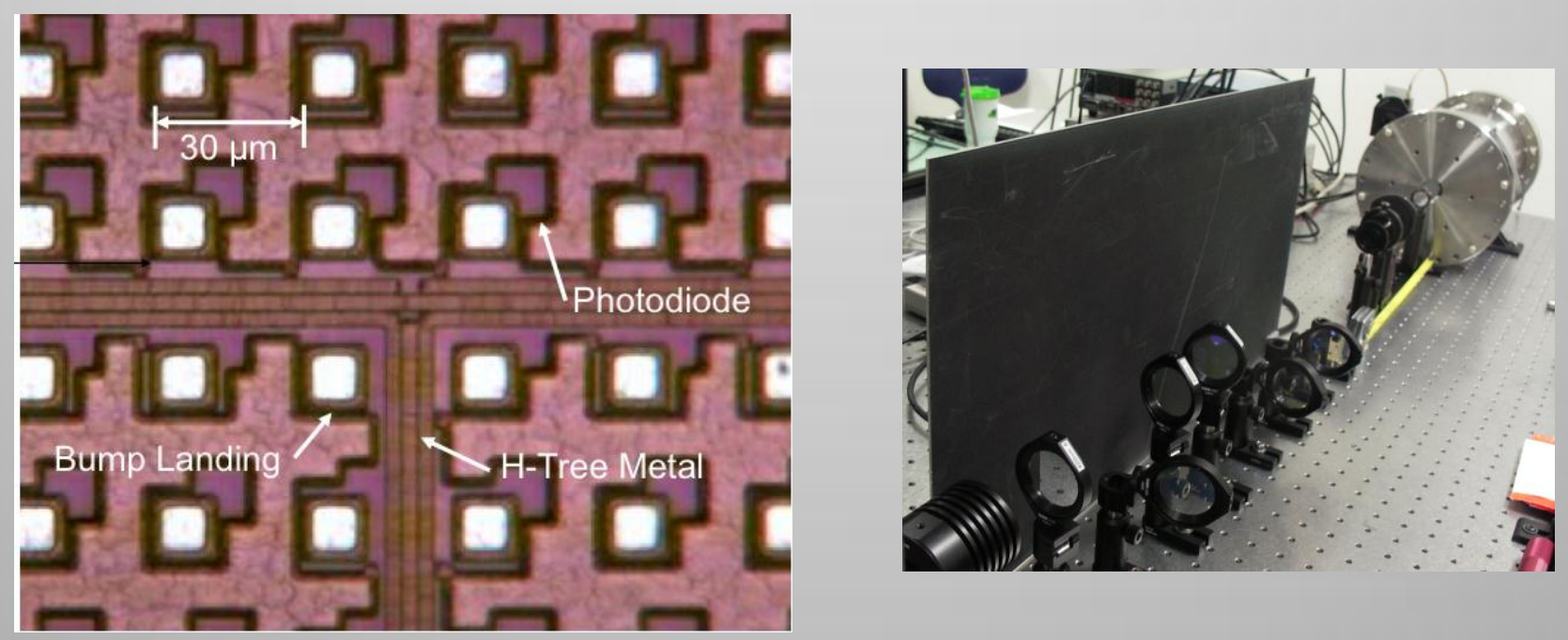


\section{Gate profiles of $512 \times 512$ ROIC}

- Gate profile measurements were taken at the minimum and maximum values for $\mathrm{V}_{\text {delay }}=.5$ and $1.7 \mathrm{~V}$

- The short pulse laser lab timing system has an RMS jitter of $\sim 25$ ps

- Amplitude noise is higher than would be indicated by laser pulse energy measurements

- Further work is being done to understand sources of jitter and noise in the measurement
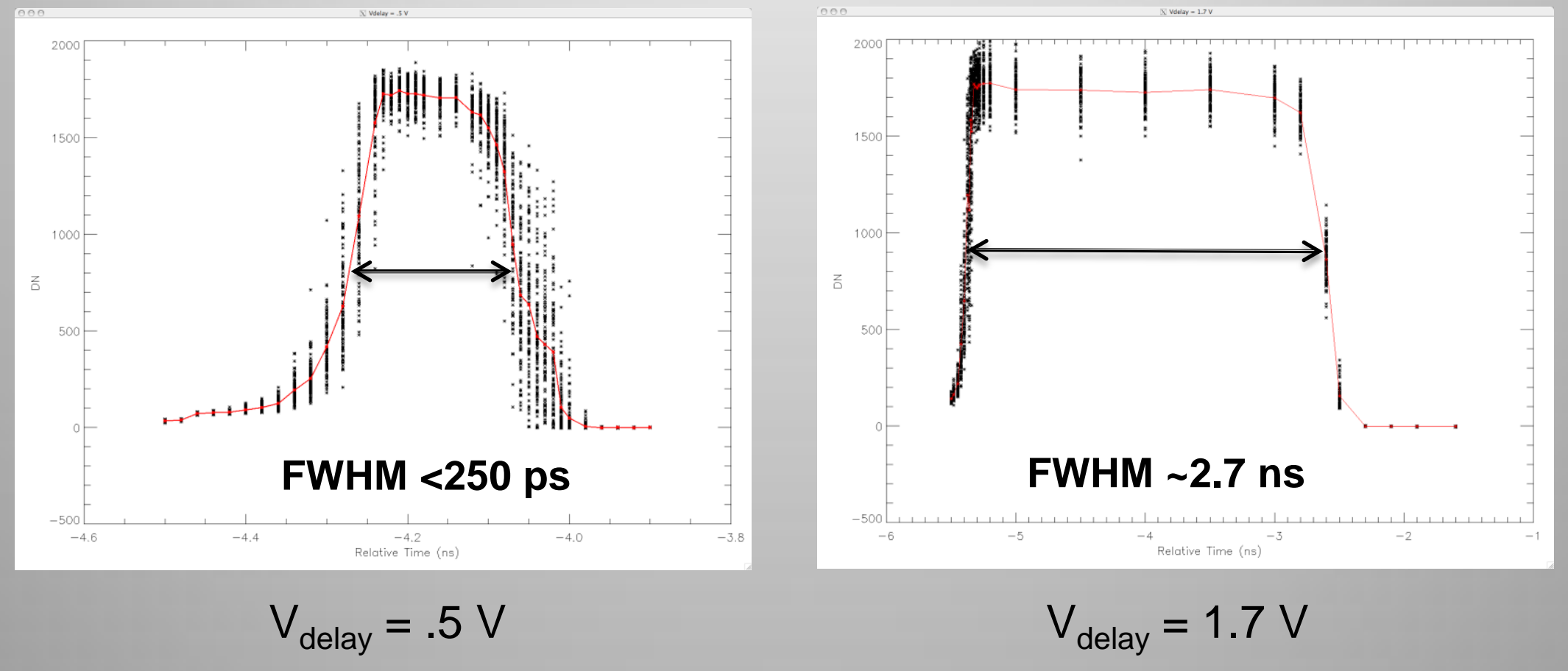


\section{Independent gating demonstration}

- Independent triggering with 100 ps delay between quadrants

- Laser/sensor timing delay in 50 ps steps 


\section{Detector array can be application specific}

- Response determined by diode thickness

Bump pads

- Thinner substrate provides faster response

- Thicker substrate needed for better QE

- Fast phosphors may be needed for $>10 \mathrm{keV}$

Imaging pixels junctions

X-Rays

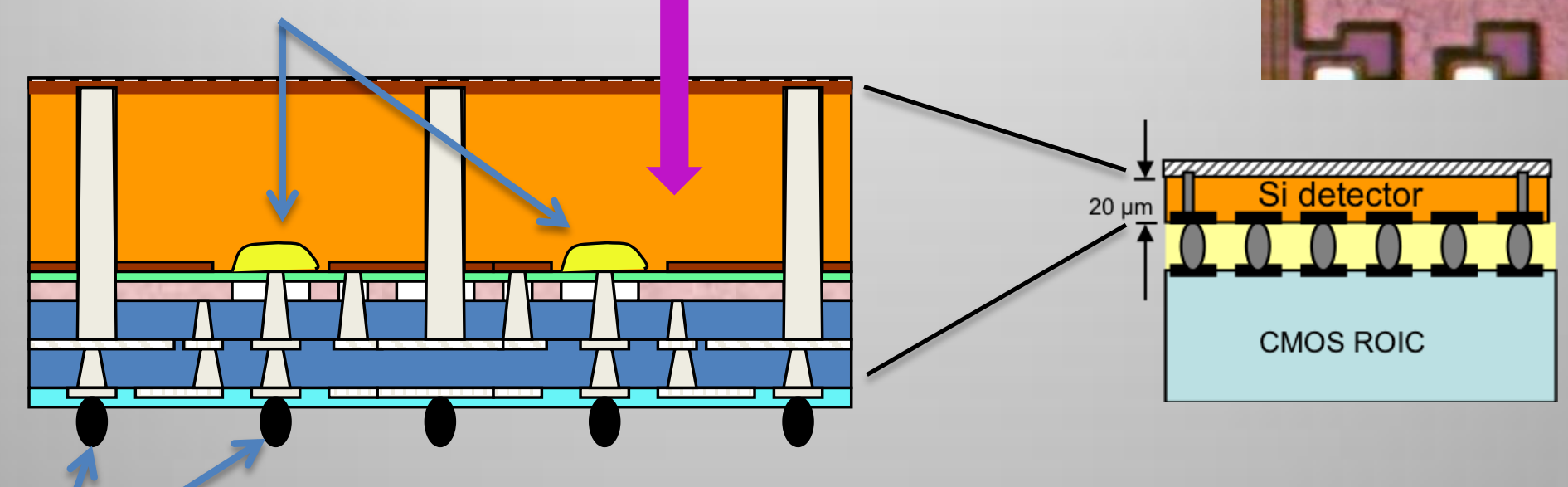

Indium bumps 


\section{Detector thickness determines speed and detector efficiency}

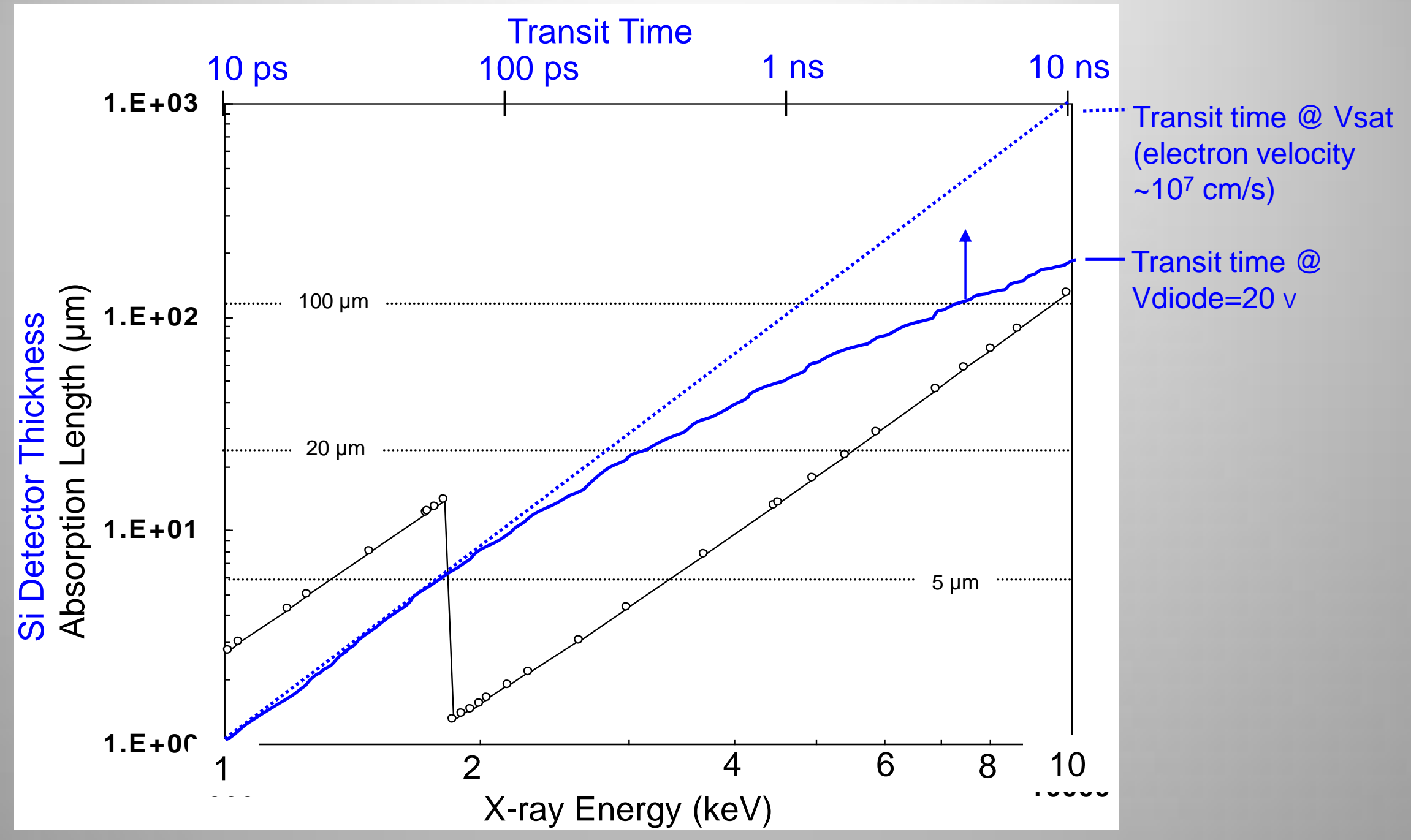




\section{Summary}

- A gated CMOS ROIC was developed for NIF imaging applications

- A 64x64 prototype tested the $\mathrm{H}$-tree and variable gating concept

- A 512x512 ROIC extended the $\mathrm{H}$-tree and demonstrated independent quadrant triggering 


\section{Future Development}

- Detector array

- Looking at options for fabricating an X-ray detector array and bump bonding to the ROIC

- An associated project is looking at multi-frame pixel version of the ROIC allowing true-single line-of-sight imaging. 
느 Lawrence Livermore 


\section{Backup and Alternate Slides}

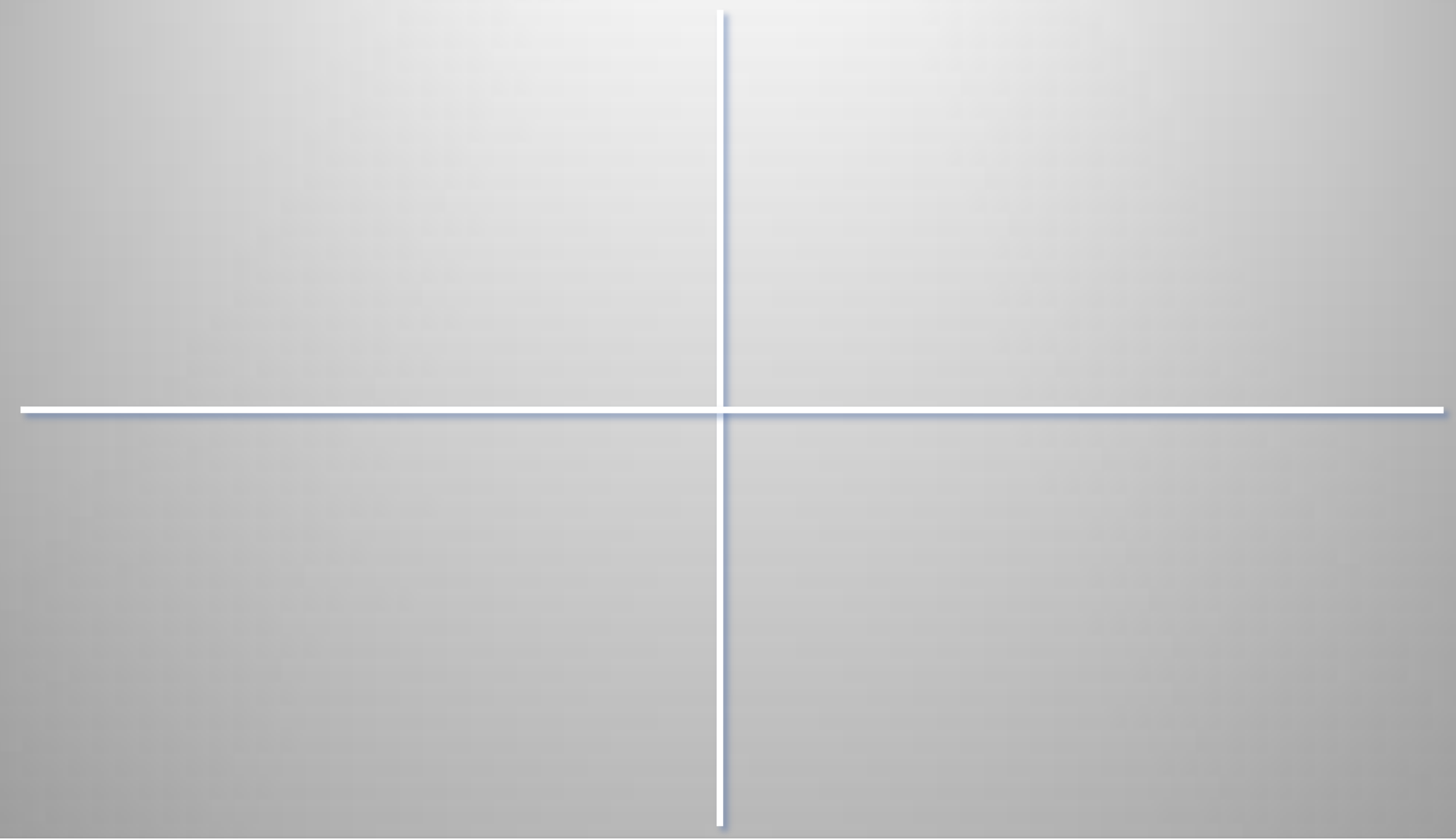




\section{The Static X-Ray Imager (SXI) takes X-ray pinhole images}
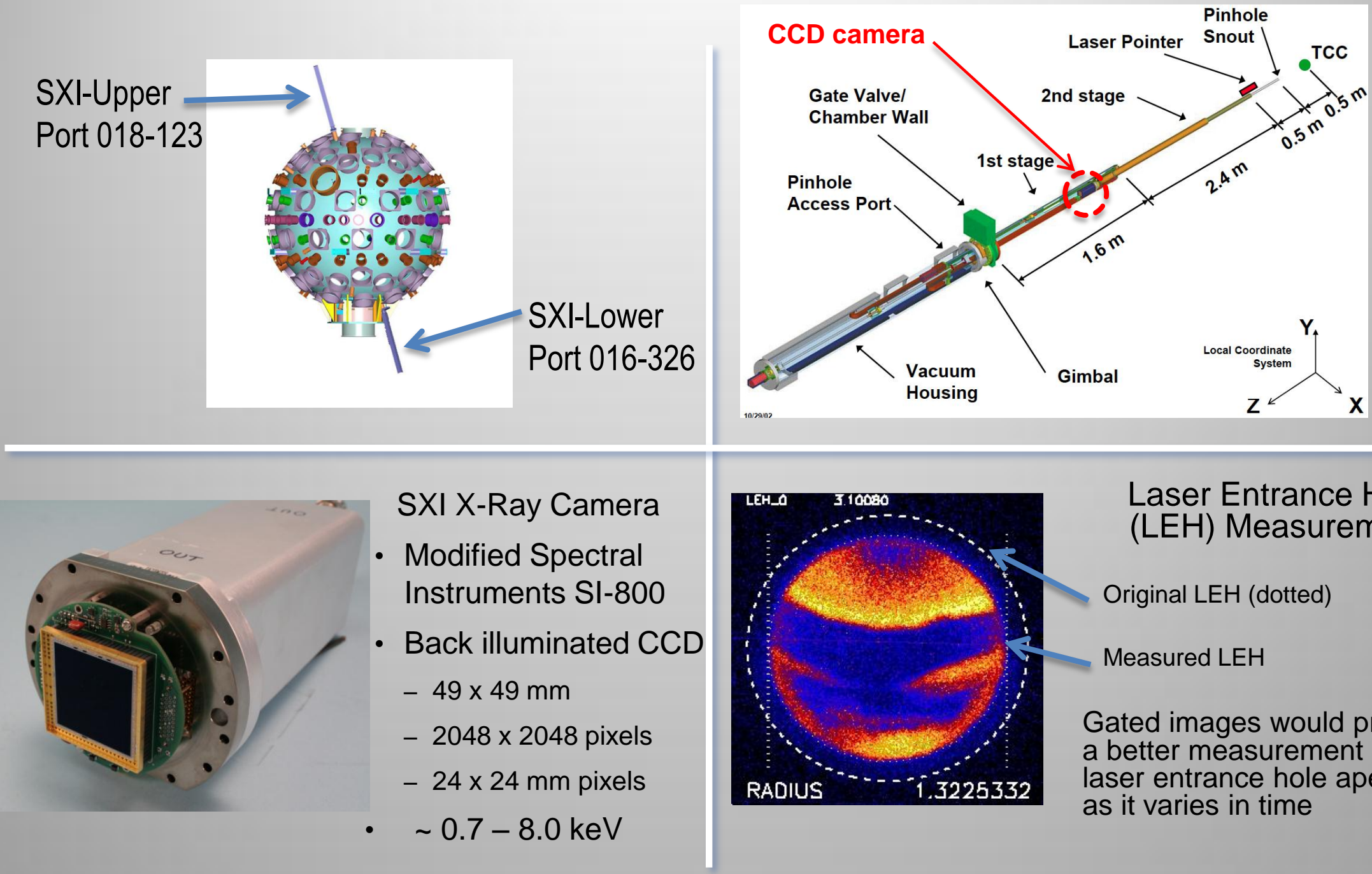

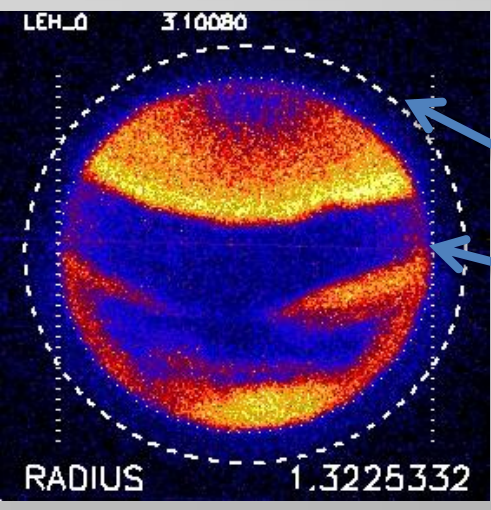

Laser Entrance Hole (LEH) Measurement

Original LEH (dotted)

Measured LEH

Gated images would provide a better measurement of the laser entrance hole aperture as it varies in time 